
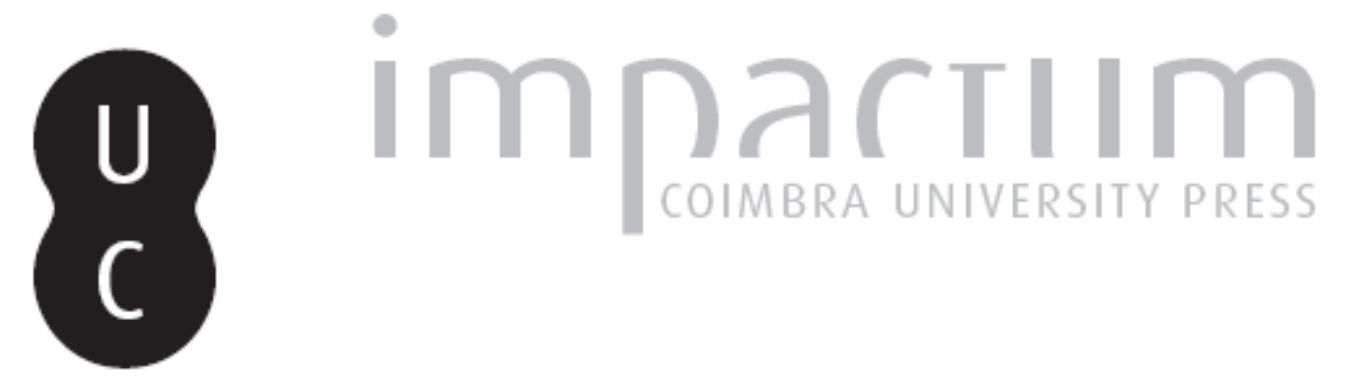

\title{
A dissertação manuscrita Hereditariedade (1910, 236 fl.) de Luís Wittnich Carrisso no contexto do "eclipse do Darwinismo"
}

Autor(es): $\quad$ Pereira, Ana Leonor; Fonseca, Pedro

Publicado por: CIAS - Centro de Investigação em Antropologia e Saúde

URL persistente:

URI:http://hdl.handle.net/10316.2/28626

DOI:

DOI:http://dx.doi.org/10.14195/2182-7982_27_2

Accessed : $\quad$ 26-Apr-2023 12:06:51

A navegação consulta e descarregamento dos títulos inseridos nas Bibliotecas Digitais UC Digitalis, UC Pombalina e UC Impactum, pressupõem a aceitação plena e sem reservas dos Termos e Condições de Uso destas Bibliotecas Digitais, disponíveis em https://digitalis.uc.pt/pt-pt/termos.

Conforme exposto nos referidos Termos e Condições de Uso, o descarregamento de títulos de acesso restrito requer uma licença válida de autorização devendo o utilizador aceder ao(s) documento(s) a partir de um endereço de IP da instituição detentora da supramencionada licença.

Ao utilizador é apenas permitido o descarregamento para uso pessoal, pelo que o emprego do(s) título(s) descarregado(s) para outro fim, designadamente comercial, carece de autorização do respetivo autor ou editor da obra.

Na medida em que todas as obras da UC Digitalis se encontram protegidas pelo Código do Direito de Autor e Direitos Conexos e demais legislação aplicável, toda a cópia, parcial ou total, deste documento, nos casos em que é legalmente admitida, deverá conter ou fazer-se acompanhar por este aviso.

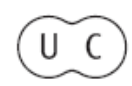




\section{Antropologia Portuguesa}

Volume $26-27 \cdot 2009-2010$

Departamento de Antropologia | Universidade de Coimbra

DARWINISMO:

revisitações, propostas, problemas 


\title{
A dissertação manuscrita Hereditariedade (1910, 236 fl.) de Luís Wittnich Carrisso no contexto do "eclipse do Darwinismo"
}

\author{
Ana Leonor Pereira, Pedro Fonseca \\ Grupo de História e Sociologia da Ciência do Centro de Estudos Interdisciplinares do Século XX (CEIS20) \\ Faculdade de Letras, Universidade de Coimbra, Portugal \\ aleop@ci.uc.pt
}

Resumo Nas décadas que se seguiram à publicação da obra fundamental de Charles Darwin, On the origin of species... (1859), o evolucionismo e a ideia de os organismos vivos partilharem uma ancestralidade comum passaram a ser geralmente aceites pela comunidade científica internacional. No entanto, a selecção natural, que o naturalista inglês apresentara como o principal mecanismo evolutivo, só passaria a gozar de uma aceitação generalizada a partir das décadas de 1930 e 1940, com o estabelecimento da Síntese Moderna. Esse período de descrédito da selecção natural, propiciado por um conjunto diversificado de factores, e agravado pela concorrência de teorias de evolução alternativas, é conhecido como o "eclipse do Darwinismo" (Peter J. Bowler). O presente trabalho tem por objectivo proceder a uma leitura compreensiva da reflexão evolucionista realizada por Luís Wittnich Carrisso na sua tese de licenciatura - Hereditariedade (1910) - mediante a sua contextualização no clima vivido durante o "eclipse do Darwinismo" (Peter J. Bowler).

Palavras-chave Darwinismo; Darwin em Portugal; “eclipse do Darwinismo”; Luís Wittnich Carrisso.

Abstract During the decades that followed the publication of Charles Darwin's
fundamental work, On the origin of species... (1859), both evolutionism and the idea that
living organisms share a common ancestry were generally accepted by the international
scientific community. However, natural selection, which the English naturalist had
proposed as the main evolutionary mechanism, was only to be generally accepted by
the 1930 's and the 1940 's through the establishment of the Modern Synthesis. That
period of discredit experienced by natural selection, triggered by a plural range of
factors, and hardened by the competition of alternative evolutionary theories, is known
as the "eclipse of Darwinism" (Peter J. Bowler). The present paper intends to provide
a comprehensive analysis of the evolutionary reflection carried out by Luís Wittnich
Carrisso in his degree thesis - Hereditariedade (1910) - by contextualizing it in the
climate lived during the "eclipse of Darwinism" (Peter J. Bowler).

Key words Darwinism; Darwin in Portugal; “eclipse of Darwinism”; Luís Wittnich Carrisso. 


\title{
O "eclipse do Darwinismo": o descrédito da Teoria da Selecção Natu- ral e a concorrência de teorias de evolução alternativas por finais do século XIX e inícios do século XX
}

\author{
"Personally, of course, I care much about Natural Selec- \\ tion; but that seems to me utterly unimportant compared to the \\ question of Creation or Modification". \\ Charles Darwin (1809-1882), 1863 [ênfase no original]. \\ “(...) Darwinism will soon be a thing of the past, a matter of \\ history; that we even now stand at its death-bed, while its friends \\ are solicitous only to secure for it a decent burial".
}

Eberhard Dennert (1861-1942), 1904: 10.

As três ideias-chave apresentadas por Charles Darwin em On the origin of species... (1859) conheceram níveis de aceitação diferenciados. O evolucionismo (evolução enquanto "facto") deixara de ser objecto de uma discussão séria por meados da segunda metade do século XIX ${ }^{1}$. Por finais do mesmo século, a descendência a partir de ancestrais comuns passou a funcionar como a matriz sobre a qual muitos naturalistas procuravam reconstruir a História da Vida ${ }^{2}$. A selecção natural, porém, só passaria a gozar de uma aceitação generalizada com a emergência da Síntese Moderna na década de 1930 (Mayr, 1982; Bowler, 1992; 2003) ${ }^{3}$. Na obra que dedicou à apresentação da nova síntese evolutiva Evolution: The Modern Synthesis (1942) - o zoólogo britânico Julian Huxley (1887-1975) informa-nos precisamente que, antes do estabelecimento da Sín-

\footnotetext{
${ }^{1}$ A maioria dos autores concorda que, poucos anos após a publicação de On the origin of species..., o evolucionismo passara a ser geralmente aceite, nomeadamente ao nível da comunidade científica. Embora os seus estudos privilegiem a sociedade britânica da segunda metade de Oitocentos, é significativa, sobretudo sob um ponto de vista de investigação historiográfica, a enorme variedade de fontes que os diferentes autores apresentam nos seus trabalhos para corroborar essa aceitação. Entre outros exemplos, Michael Ruse invoca a integração do estudo da evolução nos currículos universitários (Ruse, 2002), enquanto Alvar Ellegard refere a diminuição da oposição ao evolucionismo em revistas e jornais, incluindo publicações religiosas (Ellegard, 1990).

${ }^{2}$ De acordo com o historiador da ciência Jean Gayon, a afirmação da "árvore da vida" representou " $(\ldots)$ one of the most spectacular examples of a shift of paradigm" no sentido kuhniano (Gayon, 2003: 245).

${ }^{3}$ Por finais do século XIX e inícios do século XX, alguns opositores da Teoria da Selecção Natural defendiam mesmo que ela jamais recuperaria do estado de descrédito em que se encontrava. A frase da autoria do filósofo e naturalista alemão Eberhard Dennert, presente na abertura deste capítulo, é uma expressão inequívoca desse sentimento.
} 
tese Moderna, a selecção natural não era geralmente aceite como o principal mecanismo evolutivo. Para descrever esse clima de abandono a que muitos biólogos haviam votado a selecção natural, Julian Huxley cunhou a expressão The eclipse of Darwinism (o "eclipse do Darwinismo") (Huxley, 1942: 22-28). O historiador da ciência Peter J. Bowler, em 1983, efectuou um estudo inovador e autorizado sobre esse período de "crise" do Darwinismo, adoptando e popularizando a expressão de Julian Huxley: The eclipse of Darwinism: anti-Darwinian theories in the decades around $1900^{4}$. Neste trabalho, Peter J. Bowler analisa o período em que, devido a um conjunto diversificado de factores, a selecção natural se encontrava em descrédito. Esse descrédito (e, em alguns casos, os próprios factores que o propiciaram) favoreceu, por seu turno, o surgimento e/ ou a projecção de teorias de evolução alternativas à selecção natural. Em suma, ao contrário do evolucionismo e da ideia da partilha de uma ancestralidade comum por parte dos seres vivos, a Teoria da Selecção Natural não conheceu uma aceitação generalizada nas décadas que se seguiram à publicação de $O n$ the origin of species..., com a maioria dos biólogos a manifestar o seu apoio por teorias e mecanismos de evolução alternativos ${ }^{5}$. Assim, importa frisar que o "eclipse do Darwinismo" (Peter J. Bowler) se refere à selecção natural, independentemente de, no período considerado, se lhe reconhecer o estatuto de teoria (Peter J. Bowler) ou de hipótese (Jean Gayon): foi a selecção natural

\footnotetext{
${ }^{4}$ Entretanto, Peter J. Bowler foi subsidiando o seu estudo inicial (Bowler, 1983) com outros trabalhos (Bowler, 1992; 2003; 2005).

${ }^{5}$ Para além de Peter J. Bowler, outros autores publicaram estudos sobre o "eclipse do Darwinismo" (embora nem todos adoptem a expressão de Julian Huxley na sua abordagem ao período histórico em questão). O trabalho de Jean Gayon assume uma importância particular por completar a perspectiva de Peter J. Bowler. Enquanto este último privilegia a concorrência de teorias de evolução alternativas, o primeiro enfatiza as fragilidades internas da selecção natural, que, de resto, apresenta como uma hipótese (e não uma teoria) à espera de ser cientificamente confirmada (Gayon, 1992). James Moore, no seu trabalho sobre a história do termo "Darwinismo" ao longo da segunda metade do século XIX, fornece uma excelente descrição dos primeiros anos do "eclipse do Darwinismo", sublinhando a importância da acção dos críticos para a crescente identificação do termo "Darwinismo" com a Teoria da Selecção Natural (Moore, 1991). Ernst Mayr e Michael Ruse também disponibilizam exposições bastante completas de alguns dos factores que contribuíram para o descrédito da selecção natural, sem, no entanto, concederem uma importância tão significativa como Peter J. Bowler (ou mesmo Jean Gayon) à concorrência de teorias e mecanismos de evolução alternativos (Mayr, 1982; Ruse, 1983; 2002). Entre nós, António Braçinha Vieira, na sua recente exposição sintética da História do Darwinismo, também privilegia o tipo de abordagem adoptada por Michael Ruse e Ernst Mayr (Vieira, 2009).
} 
que se eclipsou e não o evolucionismo ou a ideia de os organismos partilharem uma ancestralidade comum. A inclusão de um esboço resumido do "eclipse do Darwinismo" (Peter J. Bowler) está fora do alcance do presente trabalho. Assim, limitar-nos-emos a referir alguns dos factores que concorreram para o descrédito da selecção natural e a enunciar as principais teorias que com ela competiam na explicação do processo evolutivo, nas décadas finais do século XIX e primeiras décadas do século XX, concedendo, no entanto, uma importância particular às matérias que revestem maior interesse para o nosso objecto de estudo.

Foram diversos os factores que concorreram para o "eclipse do Darwinismo" (Peter J. Bowler). Desde logo, os primeiros "Darwinistas", incluindo o próprio Charles Darwin, não encaravam a selecção natural como o único mecanismo da evolução, e alguns deles apoiaram mesmo teorias de evolução alternativas $^{6}$. Segundo, os finais do século XIX testemunharam o acentuar de um sentimento anti-Darwinista, devido: à crescente profissionalização da biologia (os praticantes das diferentes disciplinas biológicas apoiavam, preferencialmente, a teoria que melhor servia a resolução dos seus problemas); à relutância, sobretudo em termos morais, em aceitar uma teoria que advogava que todos os organismos (incluindo os seres humanos) estavam sujeitos às intempéries de um processo "cego", alicerçado em variações aleatórias e mudanças ambientais, cuja força orientadora era a luta pela vida e pela descendência; e à defesa da selecção natural como o único mecanismo evolutivo por parte dos neo-Darwinistas (nomeadamente August Weismann (1834-1914) e Alfred Russel Wallace), que contribuiu para alienar o apoio de todos os biólogos que já expressavam algumas dúvidas em relação à selecção natural (Bowler, 1992; 2003) ${ }^{7}$. A selecção natural foi também alvo

${ }^{6}$ A frase de Charles Darwin, presente na abertura deste capítulo, traduz a prioridade do naturalista inglês em convencer a comunidade científica do "facto" da evolução em detrimento de alcançar um sucesso imediato para a selecção natural, que apresentara, em 1859, como o principal (mas não o único) mecanismo evolutivo. Entre os primeiros apoiantes e divulgadores da teoria biológica de Charles Darwin que, além de não defenderem a selecção natural como o único mecanismo evolutivo, aderiram mesmo a perspectivas de evolução alternativas encontram-se, por exemplo: Asa Gray (1810-1888) e Ernst Haeckel (18341919), principais divulgadores do Darwinismo nos E. U. A. e na Alemanha, respectivamente; Alfred Russel Wallace (1823-1913), co-descobridor da teoria biológica de Charles Darwin; e o próprio "bulldog de Darwin", Thomas Henry Huxley (Bartholomew, 1975; Mayr, 1982; Moore, 1991; Bowler, 1992; 2003; Brooke, 2003).

${ }^{7}$ Do mesmo modo, as célebres experiências conduzidas por August Weismann nos inícios da década de 1880 - que consistiram na mutilação das caudas de ratos ao longo de 
de sucessivas críticas científicas e metodológicas, a maioria das quais surgidas ainda no tempo de Charles Darwin, com destaque para as objecções levantadas por Fleeming Jenkin (1833-1885) e George Mivart (1827-1900). Partindo da interpretação do registo fóssil, alguns críticos defendiam que a descontinuidade que nele se verificava com frequência (nomeadamente o aparecimento súbito de novas formas de vida) sugeria que a evolução não se processava de forma gradual, mas por variações abruptas/descontínuas ou "saltos súbitos"; enquanto outros viam na regularidade observável em linhas filogenéticas não relacionadas um indicador de que a variação não era aleatória (Bowler, 1992; 2003). A selecção natural tardava em ser provada experimentalmente (alguns até duvidavam que fosse possível submetê-la à experimentação científica) (Bowler, 1992), e certos produtos da evolução, nomeadamente os traços não-adaptativos ostentados por certos organismos, estavam fora do seu alcance explicativo (Mayr, 1982; Bowler, 1992; 2003). $\mathrm{O}$ desconhecimento reinante sobre a natureza das variações e o funcionamento da hereditariedade tornava a selecção natural permeável a diversas objecções: não era uma força criativa, limitando-se a eliminar as variações que não eram vantajosas; a limitada quantidade de variação sobre a qual poderia operar tornava improvável que pudesse desencadear mudanças evolutivas; e se os caracteres se misturavam no acto reprodutivo (como Charles Darwin e a maioria dos naturalistas acreditavam na segunda metade do século XIX), então a acumulação de pequenas variações vantajosas não poderia dar origem a novas espécies (Gayon, 1992; 2003; Strickberger, 1996; Ruse, 2002; Bowler, 2003). Nos inícios da década de 1860, o físicoengenheiro William Thomson (Lord Kelvin) (1824-1907), baseando-se nos novos conhecimentos da termodinâmica, concluiu que a idade da Terra era substancialmente inferior àquela que a teoria geológica de Charles Lyell (1797-1875) sugeria. A ideia de que os organismos complexos poderiam ser explicados como os produtos da acumulação gradual de pequenas variações vantajosas, ao longo de um vasto período de tempo, tornava-se insustentável perante os cálculos avançados por William Thomson, que, de resto, coloca-

gerações sucessivas, para mostrar que, ao contrário do que era postulado pelo princípio Lamarckista da hereditariedade dos caracteres adquiridos, os descendentes dos indivíduos mutilados não nasciam sem cauda - despoletaram uma reacção enérgica por parte dos proponentes do neo-Lamarckismo, que depressa contestaram os resultados apresentados pelo biólogo alemão e encetaram esforços no sentido de provar experimentalmente a validade do referido princípio Lamarckista (Mayr, 1982; Bowler, 2003). 
vam a Teoria da Selecção Natural em contradição com as leis da física. A redução da idade da Terra, embora não colocasse em causa o evolucionismo, impunha-lhe, porém, um poderoso constrangimento: o processo evolutivo tinha de ocorrer de forma mais célere do que era advogado pelos adeptos da Teoria da Selecção Natural (Burchfield, 1974; 1975; Buchwald, 1970).

Em certos casos, os mesmos factores que contribuíram para o descrédito e o abandono da Teoria da Selecção Natural, concorreram igualmente para inspirar, fortalecer, e atrair maior número de apoiantes, a teorias de evolução alternativas. De acordo com Peter J. Bowler, as principais teorias rivais da selecção natural na explicação do processo evolutivo, nos finais do século XIX e inícios do século XX, eram a Ortogénese, o Lamarckismo, e o Mutacionismo $^{8}$. Não havendo espaço para apresentar uma descrição, mesmo que resumida, de cada uma das delas, concentraremos a nossa abordagem na teoria que gozou de maior representatividade no trabalho de Luís Wittnich Carrisso (1886-1937): o Mutacionismo. Esta teoria, cujos postulados fundamentais foram apresentados pelo botânico holandês Hugo De Vries (18481935) em 1901-1903 (De Vries, 1910), alicerçava-se no modelo de evolução saltacionista do século XIX. De acordo com o Mutacionismo, a evolução não se processava pela acumulação gradual de pequenas variações vantajosas, mas sim através de variações abruptas/descontínuas ou "saltos súbitos" (agora preferencialmente designados de "mutações"), que ocorriam de forma aleatória e eram integralmente transmitidas às gerações futuras. A genética, disciplina nascida na sequência da "redescoberta" dos trabalhos de Gregor Mendel (1822-1884) em 1900, adoptaria como objectos de estudo preferenciais a variação e a hereditariedade, dois tópicos que revestiam uma importância crucial para o entendimento do processo evolutivo. No entanto, os esforços dos primeiros geneticistas (conhecidos por "Mendelianos") não se limitaram ao preenchimento dessas lacunas do conhecimento. Nos inícios do século $\mathrm{XX}$, a maioria dos geneticistas era apoiante do Mutacionismo, e acreditava que as investigações realizadas no âmbito da nova disciplina certificariam os postulados fundamentais da sua teoria evolutiva (Huxley, 1942; Gayon, 1992). Atribuída a origem das variações à mutação, os primeiros trabalhos realizados

${ }^{8}$ Além destas três teorias, a Evolução Teísta também contou com muitos adeptos na época de Charles Darwin, mas por finais do século XIX perdera já muito do seu fulgor inicial. De resto, Ernst Mayr e Jean Gayon concordam com Peter J. Bowler quanto às principais teorias alternativas da selecção natural na explicação do processo evolutivo (Bowler, 1992; 2003; Mayr, 1982; Gayon, 2003). 
na área da genética indicavam a alguns dos proponentes do Mutacionismo que a transmissão das mesmas se processava com total independência do mundo exterior. Assim, para alguns dos seus adeptos, os factores mesológicos, a adaptação, e a selecção natural, eram irrelevantes para o processo evolutivo (Huxley, 1942; Mayr, 1982; Gayon, 1992; Bowler, 2003). Como refere Peter J. Bowler: "Mendelism emerged not as the savior of Darwinism but yet as another alternative to it, precipitating a new phase of the eclipse" (Bowler, 2003: 260-261). Na mesma linha, Jean Gayon informa-nos que: "La science expérimentale de l'hérédité qui s'est mise en place autour de 1900 a d'abord semblé donner le coup de grâce au concept darwinien de sélection" (Gayon, 1992: 261). O Mutacionismo apresentava ainda respostas satisfatórias para várias das questões que outras perspectivas evolutivas, nomeadamente a Teoria da Selecção Natural, sentiam dificuldade em explicar, como, por exemplo: o surgimento e persistência de traços não-adaptativos em alguns organismos; a descontinuidade frequentemente verificada no registo fóssil; e a necessidade de a evolução ocorrer de forma célere (Bowler, 2003). Assim, com o aparecimento do Mutacionismo: "(...) both Darwinism and the alternatives were to be challenged by a new approach to the study of what had emerged as the most crucial problems: variation and heredity" (Bowler, 1992: 182). Atendendo a todos estes factores, não causará qualquer surpresa acrescentar que o Mutacionismo foi a teoria de evolução mais popular das décadas iniciais do século XX (Mayr, 1982; Gayon, 1992; Bowler, 2003).

Enunciámos, na linha de Peter J. Bowler, as principias teorias alternativas à selecção natural, concedendo um tratamento mais pormenorizado ao Mutacionismo. Importa sublinhar que essa breve apresentação está longe de fornecer uma imagem compreensiva do vasto leque de abordagens teóricas à evolução que floresceram por finais do século XIX e inícios do século XX. Peter J. Bowler, por exemplo, lembra-nos que qualquer uma das principais teorias alternativas era susceptível de diferentes interpretações pelos seus respectivos apoiantes (Bowler, 1992), enquanto Andrée Tétry nos informa que: "Au cours des trente premières années du XXe siècle est apparue une floraison de petites théories tentant d'expliquer l'évolution, au succès plus ou moins éphémère et dont il ne subsiste pas grand-choise: le psycho-lamarckisme de Pauly (1905), l'entéléchie de Driesch, la conception organismique de von Bertalanffy (1928), l'holisme de Smuts (1916), la nomogenèse de L. S. Berg (1922), l'ologenèse de D. Rosa (1909), l'aristogenèse d'Osborn, l'apogenèse de H. Przibram (1929), l'allélogenèse de A. Labbé (1924), etc" 
(Tétry, 1964: 714). Estas observações de Peter J. Bowler e Andrée Tétry são oportunas para o nosso objecto de estudo. Na nossa caracterização do Mutacionismo afirmámos que alguns dos seus apoiantes consideravam a selecção natural irrelevante para o processo evolutivo. Este tipo de posicionamento, promovido, entre outros, por William Bateson (1861-1926), Wilhelm Johannsen (1857-1927), e Thomas Hunt Morgan (1866-1945) (na fase inicial da sua carreira), não foi, porém, adoptado por todos os que filiavam a sua perspectiva evolutiva no quadro geral do Mutacionismo. Entre as excepções à anatematização do mecanismo Darwiniano no processo evolutivo encontram-se, por exemplo, o próprio Hugo De Vries e o zoólogo francês Lucien Cuénot (1866-1951). Cientistas conceituados e figuras de proa do Mutacionismo, Hugo De Vries e Lucien Cuénot foram os autores que maior influência exerceram sobre a perspectiva de evolução que Luís Wittnich Carrisso promoveu no seu trabalho de 1910. Hugo De Vries é um exemplo elucidativo da cumplicidade existente entre a genética e o Mutacionismo: um dos protagonistas da "redescoberta" dos trabalhos de Mendel, um dos primeiros praticantes da genética, e um dos principais teorizadores e proponentes do Mutacionismo. No entanto, o botânico holandês, autor de trabalhos que influenciaram profundamente o pensamento biológico da primeira década do século XX (Mayr, 1982), não alinhou na desvalorização da selecção natural defendida por outros apoiantes do Mutacionismo. Hugo De Vries acreditava que, a longo prazo, a selecção natural só permitiria a persistência de mutações que conferissem alguma vantagem adaptativa: " $B y$ far the greater number of mutations presumably perish, nipped in the bud by natural selection. Other forms may continue for one or two years, but after a time they too disappear. It is only a very few which ultimately come to take part in the struggle for existence" (De Vries, 1910: 203). Como nos informa Jean Gayon, o botânico holandês "(...) ne rejetait pas en bloc le concept de sélection naturelle. La sélection naturelle agit après coup, en exterminant les formes qui ne sont pas adaptées. Elle a en cela un rôle régulateur fondamental. Mais ce n'est pas en elle qu'il faut chercher l'origine des espèces. La sélection naturelle ne transforme rien, elle ne fait jamais que sanctionner a posteriori des variations brusques et massives dans l'apparition desquelles elle ne joue aucun rôle" [ênfase do autor] (Gayon, 1992: 266). Deste modo, Hugo De Vries reconhecia a importância da selecção natural no processo evolutivo, atribuindo-lhe, todavia, uma função distinta daquela que Charles Darwin originalmente lhe conferira: "In a word, from the standpoint of the 
theory of mutation it is clear that the role played by natural selection in the origin of species is a destructive, and not a constructive one" (De Vries, 1910: 212). De resto, o botânico holandês não apresentou a sua Teoria da Mutação como uma alternativa à Teoria da Selecção Natural (Mayr, 1982; Bowler, 2003). Muito pelo contrário, Hugo De Vries afirmou explicitamente que os seus trabalhos se realizavam de acordo com a tradição Darwiniana: "My work claims to be in full accordance with the principles laid down by Darwin, and to give a thorough and sharp analysis of some of the ideas of variability, inheritance, selection and mutation, which were necessarily vague at his time" (De Vries, 1910 in Bowler, 1992)9. Lucien Cuénot, por seu turno, alterou por diversas vezes o seu posicionamento em relação ao processo evolutivo (Schmitt, 2002). Apoiante do neo-Darwinismo de August Weismann desde 1894 (Gayon e Burian, 2002; Schmitt, 2002), o zoólogo francês aderiu ao Mutacionismo em 1901, passando, desde então, a perspectivar a selecção natural como um agente destrutivo, e não como a principal força responsável pelo surgimento de novas espécies (Gayon, 1992; Gayon e Burian, 2000). Mantendo o lugar central do processo evolutivo reservado à mutação (só as mutações têm a capacidade de dar origem a novas espécies), e reafirmando a acção destrutiva da selecção natural, Lucien Cuénot desenvolveu uma teoria de evolução que enfatizava igualmente a importância da adaptação: a "Teoria da Pré-adaptação". De acordo com esta teoria, elaborada durante os anos iniciais do século XX e cujos postulados fundamentais Lucien Cuénot apresentou apenas em 1914 (Cuénot, 1914 in Tétry, 1996), a selecção natural era incapaz de criar um órgão novo através da adaptação gradual de uma espécie a novas condições mesológicas. Para o zoólogo francês, o sucesso das espécies dependia do surgimento de estruturas por variação aleatória que lhes permitiriam estar "pré-adaptadas" a novas condições que, eventualmente, encontrariam. $\mathrm{O}$ autor entendia por

\footnotetext{
${ }^{9}$ Saindo do domínio das teorias de evolução, mas com interesse para a nossa abordagem, importa acrescentar que os trabalhos de Hugo De Vries sobre a hereditariedade se inspiraram na teoria da hereditariedade de Charles Darwin (a Pangénese), e que o autor acreditava ter comprovado alguns dos postulados da mesma (Lenay, 1996; Endersby, 2003). O botânico holandês manteve correspondência com Charles Darwin, que conheceu pessoalmente em 1877. Em homenagem ao naturalista inglês, cuja obra de 1859 despertara o seu interesse para o evolucionismo, Hugo De Vries baptizou as unidades de hereditariedade de "pangenes" - expressão de onde posteriormente se originou o termo "gene" da autoria de Wilhelm Johannsen (Bowler, 1978; van der Pas, 1970).
} 
"pré-adaptações”, “(...) les caractères indifférentes ou semi-utiles chez une espèce et que peuvent devenir des adaptations évidentes si l'espèce adopte un nouvel habitat ou requiert de nouvelles moeurs, changement rendu possible grâce, précisément, à l'existence des préadaptations" (Cuénot, 1914 in Tétry, 1996). A selecção natural, por seu turno, era o agente responsável pela eliminação dos organismos que não eram bem sucedidos na sua adaptação ao meio: 'L'adaptation des êtres à leur milieu est un phénomène universel; non adaptés, ils disparaîtraient rapidement" (Cuénot, 1914 in Tétry, 1996). Tal como Hugo De Vries, Lucien Cuénot também fez questão de filiar a sua teorização evolucionista na tradição Darwiniana: “C'est Darwin qui a le premier signalé, de la façon la plus claire, des cas de préadaptations; mais il n'a pas songé à tirer parti de l'idée" (Cuénot, 1914 in Tétry, 1996). Hugo De Vries e Lucien Cuénot reconhecem, assim, a importância da selecção natural no processo evolutivo, embora a função reservada ao mecanismo Darwiniano se distancie do papel que Charles Darwin originalmente lhe atribuíra: para Charles Darwin a selecção (natural ou artificial) modificava as variedades, enquanto para Hugo De Vries e Lucien Cuénot a sua acção se limitava à eliminação daquelas que se revelavam menos vantajosas.

\section{A perspectiva de evolução de Luís Wittnich Carrisso em Heredita- riedade (1910): a validação da selecção natural e da adaptação no quadro geral do Mutacionismo}

"Mais de cincoenta annos decorreram sobre a obra de Darwin [On the origin of species...(1859)], e no grande edificio cujos alicerces elle fundou, ainda ha muito que trabalhar".

Luís Wittnich Carrisso, 1910: 8 [sublinhado no original].

“(...) a ideia de que as especies se originaram umas das outras por mutações nada tem de anti-scientifico, e permitte dar uma explicação satisfatoria de alguns pontos escuros, que as antigas concepções não conseguiam esclarecer".

Luís Wittnich Carrisso, 1910: 225

Antes de iniciarmos a análise da dissertação manuscrita intitulada Hereditariedade de Luís Wittnich Carrisso no contexto do "eclipse do Darwinismo" (Peter J. Bowler), importa introduzir algumas informações sobre o autor e o seu trabalho. O manuscrito "Hereditariedade" consiste numa 
dissertação para o acto de licenciatura da secção de ciências histórico-naturais da então Faculdade de Filosofia Natural da Universidade de Coimbra, tendo a sua defesa decorrido no dia 14 de Junho de 1910 (Annuário da Universidade de Coimbra, 1910-1911). O seu autor, Luís Wittnich Carrisso, foi discípulo de Júlio Augusto Henriques (1834-1924) (Fernandes, 1939), um grande cientista pioneiro na recepção do Darwinismo em Portugal (Pereira, 2001). Doutorado em 1911 e, desde 1912, professor assistente de ciências biológicas da então recém-criada Faculdade de Ciências da Universidade de Coimbra, Wittnich Carrisso tornou-se professor catedrático e director do Jardim Botânico em 1918 (sucedendo neste cargo precisamente a Júlio Augusto Henriques). Wittnich Carrisso teve uma carreira profissional notável que agora não podemos expor. Importa, no entanto, ter presente que no momento em que redigiu Hereditariedade, Wittnich Carrisso era um jovem candidato ao grau de licenciado, que concluíra a sua formatura apenas dois anos antes (1908). Considerado globalmente, o trabalho de Wittnich Carrisso apresenta-se como um longo "estado da arte" sobre a hereditariedade e a variação por volta de 1910. Todavia, apesar da especificidade dos seus objectos de estudo, Wittnich Carrisso estava consciente da importância que eles assumiam para o entendimento do processo evolutivo. Logo no capítulo introdutório, o autor defende que só um conhecimento mais aprofundado das leis da variação e da hereditariedade poderia proporcionar uma solução para a questão da origem das espécies (Carrisso, 1910: 3-8), e dedica mesmo o último capítulo do seu trabalho a esta matéria: "A origem das espécies e os recentes trabalhos sobre variação" (Carrisso, 1910: 218-236). De resto, Wittnich Carrisso lembra que fora precisamente Darwin, quem, em 1859, chamara a atenção dos naturalistas para as questões da variação e da hereditariedade (Carrisso, 1910: 10). Atendendo aos objectivos do nosso trabalho, a análise da exposição de Wittnich Carrisso assentará em três eixos fundamentais. Primeiro, a posição do autor em relação à Teoria da Selecção Natural. Segundo, e em estreita conexão com o primeiro ponto, a abordagem do autor às principais teorias de evolução alternativas. Terceiro, e englobando os dois pontos anteriores, a contextualização do trabalho no clima vivido durante o "eclipse do Darwinismo" (Peter J. Bowler).

No que diz respeito às três ideias-chave apresentadas por Charles Darwin em On the origin of species... (evolucionismo, descendência a partir de uma ancestralidade comum, e a selecção natural enquanto principal mecanismo evolutivo), Wittnich Carrisso assume posições distintas. A 
evolução enquanto "facto" não é sequer colocada em causa. A partilha de uma ancestralidade comum pelos organismos também não é questionada, sendo, inclusive, utilizada como um exemplo da semelhança existente entre as teorias evolutivas de Darwin e de Lamarck que o autor promove no seu trabalho. No que diz respeito ao papel da selecção natural no processo evolutivo, a posição de Wittnich Carrisso é menos entusiasta e muito mais complexa. Primeiro, o autor promove um "Darwinismo" heterodoxo, distanciando-se categoricamente do dogmatismo seleccionista postulado pelo neo-Darwinismo de August Weismann. Segundo, na linha do Mutacionismo, o autor não considera a selecção natural como uma "força criativa", embora lhe reconheça, em sintonia com o pensamento evolucionista de Hugo De Vries e de Lucien Cuénot, uma função destrutiva. Ao longo do seu trabalho, Wittnich Carrisso promove um "Darwinismo" aberto a outros mecanismos evolutivos para além da selecção natural, nomeadamente às variações bruscas e à hereditariedade dos caracteres adquiridos. Nesta linha, o autor lembra que o próprio Charles Darwin aceitara o referido princípio Lamarckista (Carrisso, 1910: 15, 45, 221) e admitira a possibilidade de variações bruscas darem origem a novas formas de vida (Carrisso, 1910: 223-224). Convencido que as teorias evolutivas de Lamarck e de Darwin não apresentam diferenças significativas entre si, excepção feita à importância que o segundo reservava à selecção natural, Wittnich Carrisso defende que o nível de sucesso diferenciado que as teorias conheceram se deveu, sobretudo, à sua respectiva fundamentação: Lamarck não sustentou adequadamente a sua teoria e passou quase despercebido; Darwin, pelo contrário, alicerçou a sua teoria numa enorme quantidade de observações e presidiu a uma revolução científica (Carrisso, 1910: 11-12, 221). O autor afirma ainda que a falta de compreensão da teoria de Lamarck em França, foi um dos factores que concorreu para a dificuldade de implantação da teoria de Darwin em terras gaulesas (Carrisso, 1910: 13). A promoção de um "Darwinismo" heterodoxo (que, em particular, não rejeitava o princípio Lamarckista da hereditariedade dos caracteres adquiridos) e a desvalorização do papel da selecção natural no processo evolutivo, colocavam Wittnich Carrisso em rota de colisão com o dogmatismo seleccionista postulado pelo neo-Darwinismo de August Weismann. Contra o biólogo alemão, o autor defende que as suas célebres experiências, que se propunham desacreditar definitivamente a hereditariedade dos caracteres adquiridos, não apresentaram resultados conclusivos, nem colocaram um ponto final na discussão entre Lamarckistas e neo- 
Darwinistas (Carrisso, 1910: 14-15, 191-203) ${ }^{10}$. Além disso, o autor refere que experiências recentes indicavam que os dois princípios Lamarckistas (a hereditariedade dos caracteres adquiridos; o uso e desuso de órgãos) eram válidos em algumas circunstâncias (Carrisso, 1910: 50-52).

A afinidade de Wittnich Carrisso por um "Darwinismo" heterodoxo, não ofusca, porém, o apoio confesso do autor pelo "(...) novo "credo" transformista que ja muitos biologos do velho e do novo mundo, abraçaram com fervor" (Carrisso, 1910: 230): o Mutacionismo. Nesta linha, o autor considera a "redescoberta" dos trabalhos de Mendel sobre a hereditariedade e os recentes trabalhos de Hugo De Vries sobre a variação como "(...) os acontecimentos mais importantes da Biologia nos ultimos dez annos" (Carrisso, 1910: 75). A sua adesão ao Mutacionismo processou-se, todavia, em sintonia com as perspectivas de evolução de Hugo De Vries e de Lucien Cuénot, duas influências que condicionariam o seu entendimento da selecção natural e da adaptação. Assim, o autor defende que a selecção natural não é uma força criativa no processo evolutivo, fazendo, inclusive, referência a algumas experiências recentes que mostravam que a acção da selecção sobre diferentes tipos de variações era nula ou muito limitada (Carrisso, 1910: 130-138, 226). No entanto, na linha do que era postulado por Hugo De Vries e por Lucien Cuénot, Wittnich Carrisso está longe de descartar a acção da selecção natural no processo evolutivo, reservando-lhe a função de eliminar as mutações não vantajosas (Carrisso, 1910: 225). A própria definição que o autor apresenta da teoria de Darwin sublinha a acção destrutiva que atribuía à selecção natural: "Darwin explicava a differenciação progressiva das especies pela acção combinada de dois factores: a variação, que determinava a existência de formas differentes, e a acção selectiva do meio, verdadeiro crivo, que só deixava persistir as formas melhor adaptadas" [sublinhado no original] (Carrisso, 1910: 10-11). De acordo com a perspectiva de evolução de Wittnich Carrisso, só as mutações têm a capacidade para dar origem a novas espécies (Carrisso, 1910: 139, 225, 228), mas a sobrevivência das novas formas de vida depende da selecção natural, que “(...) só deixará persistir as formas que, por um mero acaso, se encontrem adaptadas ao meio" (Carrisso, 1910: 149). O autor acrescenta ainda que

${ }^{10}$ A demarcação de Wittnich Carrisso de August Weismann não se limita às teorias de evolução. No domínio concreto das teorias da hereditariedade, o autor português promove a "Teoria Bioquímica" de Félix Le Dantec (1869-1917), referindo que a "Teoria do Germoplasma" do biólogo alemão se encontrava bastante desacreditada (Carrisso, 1910: 205-217). 
os factores mesológicos não têm qualquer influência no sentido em que as mutações são produzidas (Carrisso, 1910: 148), embora se afigurasse provável que o seu (mutações) aparecimento se devesse a mudanças bruscas das condições ambientais (Carrisso, 1910: 150-157, 227-230). Wittnich Carrisso salvaguardava, assim, a importância dos factores mesológicos, sublinhando, todavia, que a sua influência na produção de mutações não era um dado confirmado (Carrisso, 1910: 227). O autor fornece um exemplo hipotético que ilustra bem a sua perspectiva evolutiva de matriz mutacionista, e que vale a pena transcrever: "Consideremos uma especie qualquer, vivendo $n$ ' um determinado meio, e supponhamos que n' esse meio se produzem (...) modificações de certa importancia. Os individuos dessa especie darão origem a mutações; e se dos mutantes algum estiver adaptado, por acaso às novas condicções esse propagar-se ha" [sublinhado no original] (Carrisso, 1910: 229). Embora o lugar central da sua perspectiva de evolução esteja reservado à mutação, o autor não a considera como o mecanismo exclusivo da evolução, sublinhando a importância de outros agentes, como a selecção natural, a adaptação, e os factores mesológicos. O exemplo hipotético não contempla (pelo menos de forma rigorosa) a noção de "pré-adaptação" de Lucien Cuénot. Como vimos, o zoólogo francês afirmava que as "préadaptações" eram importantes na colonização de um novo meio. No seu exemplo hipotético, Wittnich Carrisso refere a adaptação a novas condições no mesmo meio. De qualquer modo, noutro ponto do seu trabalho, Wittnich Carrisso parece ter cumprido integralmente esse requisito: "As mutações não se produzem n'um sentido determinado; teem logar ao acaso dando origem a modificações de toda e qualquer natureza. Das formas novas assim originadas persistirão evidentemente aquellas que encontrarem um meio ambiente propicio. Todas as outras serão rigorosamente eliminadas pela acção selectiva do meio" (Carrisso, 1910: 227-228). As duas últimas frases estão em sintonia com a noção de "pré-adaptação", no entanto, importa frisar que Wittnich Carrisso, em momento algum do seu trabalho, distingue este tipo de adaptações ou emprega os termos "pré-adaptação" ou mesmo "Teoria da Pré-adaptação" "I Independentemente de ter ou não aderido integralmente ao conceito de "pré-adaptação" de Lucien Cuénot, a importância que o autor

${ }^{11}$ Por razões óbvias, Wittnich Carrisso não teve acesso ao texto de 1914 em que Lucien Cuénot apresentou os postulados fundamentais da sua teoria evolutiva. De qualquer modo, o autor português refere o trabalho em que Lucien Cuénot baptizou a sua nova perspectiva de evolução de "Teoria da Pré-adaptação" (1909) (Carrisso, 1910: 236). 
atribui à selecção natural e à adaptação na sua perspectiva de evolução é inegável. O autor afastava-se, assim, do conjunto de proponentes do Mutacionismo que defendia a auto-suficiência das mutações na explicação do processo evolutivo. E, ao garantir às mutações o lugar central na evolução, distanciava-se igualmente dos neo-Darwinistas, que não reconheciam outro mecanismo evolutivo para além da selecção natural. Nas páginas finais do seu trabalho, Wittnich Carrisso faz questão de sublinhar, que, ao contrário da evolução gradual defendida pelos neo-Darwinistas, o Mutacionismo era conciliável com as recentes estimativas da idade da Terra, bem como com a descontinuidade verificada no registo fóssil (embora, neste último caso, o autor acrescente que o registo fóssil indicava que a evolução também ocorria de forma gradual) (Carrisso, 1910: 232-234). O seu entusiasmo por um Mutacionismo que compreendia a acção de outros mecanismos para além das mutações contrasta com a sua posição em relação às outras teorias alternativas. A Evolução Teísta e a Ortogénese estão simplesmente ausentes do seu trabalho. Em relação à primeira, o autor não faz sequer qualquer referência a agentes sobrenaturais. Em relação à segunda, deixa bem claro que as mutações são produzidas de forma aleatória. No que diz respeito ao neo-Lamarckismo, o autor atribui uma importância hipotética aos factores mesológicos na sua perspectiva de evolução, mas coloca a validade do princípio da hereditariedade dos caracteres adquiridos, postulado central do neo-Lamarckismo, em suspenso. Importa sublinhar que a perspectiva de evolução de Wittnich Carrisso não contempla, nem sequer admite como hipótese, qualquer tipo de progressão necessária, sentido teleológico, ou componente vitalista. De resto, e como vimos num dos exemplos hipotéticos do autor, Wittnich Carrisso deixa bem claro que as mutações, pedras basilares do processo evolutivo, são produzidas de forma aleatória e não direccionada: “As mutações não se produzem n'um sentido determinado; teem logar ao acaso dando origem a modificações de toda e qualquer natureza" (Carrisso, 1910: 227-228).

O trabalho de Wittnich Carrisso espelha bem o clima vivido durante o "eclipse do Darwinismo" (Peter J. Bowler). Desde logo, o autor promove um "Darwinismo" heterodoxo à imagem de Charles Darwin e dos primeiros "Darwinistas", distanciando-se e criticando explicitamente o dogmatismo seleccionista de August Weismann, e recusando-se a aceitar os resultados das experiências do biólogo alemão que se propunham desacreditar definitivamente a hereditariedade dos caracteres adquiridos. Wittnich Carrisso não 
manifesta, porém, qualquer constrangimento de ordem moral em relação ao mecanismo Darwiniano. É certo que, por um lado, omite a luta pela vida e pela descendência da sua definição da teoria biológica de Charles Darwin, mas, por outro, atribui uma função destruidora (e não criativa) à selecção natural. Tratando-se o seu trabalho de uma exposição sobre a hereditariedade e a variação, o autor está plenamente consciente da sua importância para o evolucionismo, manifestando o seu apoio pela teoria evolutiva que mais se coaduna com a realidade dos seus objectos de estudo (o Mutacionismo). Na mesma linha, a maioria das experiências a que faz referência certificam os postulados fundamentais do Mutacionismo, teoria de evolução que, como o autor sublinha, conseguia explicar a descontinuidade frequentemente verificada no registo fóssil e era compatível com as novas estimativas da idade da Terra. Importa igualmente referir que, ao nível da História da Ciência em Portugal, o trabalho de Wittnich Carrisso prolonga a tendência oitocentista do nosso país para se assumir sobretudo como um centro receptor de inovações científicas produzidas nos países mais desenvolvidos (Pereira e Pita, 1993). Todos os trabalhos citados pelo autor ao longo da sua exposição são de autoria estrangeira, com um claro predomínio de autores franceses e, em menor número, de traduções francesas de outras obras estrangeiras ${ }^{12}$. Atendendo à influência de autores franceses na elaboração do seu trabalho, não deixa de ser significativo que Wittnich Carrisso tenha privilegiado os trabalhos do botânico holandês Hugo De Vries (embora traduzidos para a Língua Francesa) e de Lucien Cuénot. O zoólogo francês foi uma excepção à tendência geral dos biólogos franceses para, por um lado, apoiarem teorias evolutivas antiDarwinistas, nomeadamente de inspiração neo-Lamarckista (Mayr, 1982)13,

${ }^{12}$ Da totalidade dos trabalhos citados por Wittnich Carrisso ao longo da sua exposição (que não inclui uma secção bibliográfica), encontram-se: dez de autores franceses (de entre os quais, quatro são da autoria de Lucien Cuénot), duas traduções francesas (de trabalhos de Hugo De Vries), um de um autor britânico, outro de um autor norte-americano, apenas uma tradução portuguesa, e nenhum trabalho original em Língua Portuguesa. É certo que em 1910 a genética ainda não era leccionada como disciplina autónoma em Portugal (só o seria a partir de 1929 na Universidade de Coimbra), o que poderá ajudar a explicar, em parte, a completa ausência de referências a trabalhos originais portugueses sobre a variação e a hereditariedade na sua exposição. Pela altura em que Wittnich Carrisso elaborou a sua exposição, poucos autores portugueses tinham publicado trabalhos sobre este tema.

${ }^{13}$ Peter J. Bowler informa-nos, por exemplo, que a maioria dos biólogos franceses defendia que Lamarck (e não Darwin) era o verdadeiro fundador do evolucionismo (Bowler, 2003). 
e, por outro, colocarem resistências à afirmação da genética (Mayr, 1982; Burian et al., 1988; Gayon e Burian, 2000; Bowler, 2003) - Lucien Cuénot foi mesmo um dos mais influentes geneticistas das décadas iniciais do século $\mathrm{XX}^{14}$. Através da sua inclinação para as teorias evolutivas de Hugo De Vries e de Lucien Cuénot, Wittnich Carrisso integrava a componente-chave da teoria biológica de Charles Darwin (a selecção natural) na sua perspectiva de evolução em pleno "elipse do Darwinismo" (Peter J. Bowler). É certo que, em virtude da sua integração numa perspectiva evolutiva de matriz mutacionista, a selecção natural adquirira uma significação parcialmente diferente daquela que Charles Darwin originalmente lhe atribuíra. O mesmo se aplica a outra componente-chave do Darwinismo, que Wittnich Carrisso, através da influência da "Teoria da Pré-adaptação" de Lucien Cuénot, também valorizava na sua perspectiva evolutiva: a adaptação. Importa acrescentar que o conceito de "pré-adaptação" e a acção destrutiva da selecção natural no processo evolutivo não foram negligenciados por Julian Huxley aquando da sua apresentação da Síntese Moderna em 1942. Em relação ao conceito de "pré-adaptação", Julian Huxley afirmava que "From the point of view of selection, adaptations fall into two categories - those of preadaptations fitting an organism for a different environment or mode of life from the outset, and adaptations in the ordinary sense, gradually evolved within the normal environment, whether stable or changing" (Huxley, 1942: 419), e lembrava igualmente que "(...) preadaptation of various kinds has clearly played a not inconsiderable role in evolution" (Huxley, 1942: 457). Quanto à acção destrutiva da selecção natural no processo evolutivo, Julian Huxley defende que o mecanismo Darwiniano não desempenha um papel tão limitado na evolução, mas a justificação que introduz não invalida a posição partilhada por Hugo De Vries, Lucien Cuénot e Luís Wittnich Carrisso: "(...) the statement that selection is a destructive agency is not true, if it is meant to imply that it is merely destructive (...). Neither mutation nor selection alone is creative of anything important in evolution; but the two in conjunction are creative" [ênfase do autor] (Huxley, 1942: 28). Na mesma linha, Jean Gayon chama a nossa atenção para o facto de o neo-Darwinismo moderno ser, no fundo, uma teoria de "mutação-selecção": "Tous les grands

${ }^{14}$ Por 1930, Lucien Cuénot era o único biólogo francês que havia realizado investigações significativas na área da genética, apesar de ter abandonado a prática dessa disciplina por 1914. Entre outros contributos importantes, Lucien Cuénot foi, juntamente com William Bateson, um dos pioneiros da extensão do Mendelismo ao mundo animal (Gayon e Burian, 2000). 
darwiniens de ce siècle [século XX], de R. A. Fisher à E. Mayr, ont répété à la suite de De Vries que l'évolution est un processus à deux étapes, dans lequel le rythme de la sélection dépend en dernier recours du rythme des mutations" (Gayon, 1992: 277).

Em suma, a perspectiva de evolução de Luíz Wittnich Carrisso valorizava, em pleno "eclipse do Darwinismo" (Peter J. Bowler), duas componentes-chave da teoria biológica de Charles Darwin (a selecção natural e a adaptação), embora, em sintonia com os postulados fundamentais do Mutacionismo, o lugar central do processo evolutivo estivesse reservado à mutação. Questionando-se, no entanto, sobre a possibilidade de a mutação poder explicar, por si só, todos os fenómenos biológicos, Wittnich Carrisso concluiu o seu trabalho com uma prudência que o entusiasmo pelo Mutacionismo na época não recomendava, mas que a emergência da Síntese Moderna, alicerçada nas contribuições de diferentes disciplinas biológicas, revelaria acertada: "Talvez n'este assumpto, como em tantos outros, a melhor solução esteja no ecletismo" (Carrisso, 1910: 235).

Em termos de história da ciência, este artigo mostra como é complexo e moroso o processo de afirmação da cientificidade de conceitos e de teorias, mesmo no campo das ciências da vida. No livro manuscrito de Wittnich Carrisso, intitulado Hereditariedade, é patente o esforço do jovem investigador português, acabando por adoptar uma posição ecléctica, aberta a subsequentes progressos na investigação científica.

\section{Referências bibliográficas}

Annuário da Universidade de Coimbra, Anno lectivo 1910-1911.

Bartholomew, M. 1975. Huxley's defence of Darwin. Annals of Science, 32(6): 525-535.

Bowler, P. J. 1978. Hugo De Vries and Thomas Hunt Morgan: the mutation theory and the spirit of Darwinism. Annals of Science, 35(1): 55-73.

Bowler, P. J. 1983. The eclipse of Darwinism: anti-Darwinian theories in the decades around 1900. Baltimore, The Johns Hopkins University Press.

Bowler, P. J. 1992. The eclipse of Darwinism: anti-Darwinian theories in the decades around 1900. Baltimore, The Johns Hopkins University Press.

Bowler, P. J. 1996. Life's splendid drama: evolutionary biology and the reconstruction of life's ancestry, 1860-1940. Chicago, The University of Chicago Press. 
Bowler, P. J. 2003. Evolution: the history of an idea. 3rd edition. Berkeley, University of California Press.

Bowler, P. J. 2005. Revisiting the eclipse of Darwinism. Journal of the History of Biology, 38(1): 19-32.

Brooke, J. H. 2003. Darwin and Victorian Christianity. In: Hodge, J.; Radick, G. (eds.) The Cambridge Companion to Darwin. Cambridge, Cambridge University Press: 192-213.

Buchwald, J. Z. 1970. William Thomson (Lord Kelvin) (1824-1907). In: Gillispie, C. C. (ed.) Dictionary of scientific biography. Vol. XIII. New York, Charles Scribner's Sons: 374-388.

Burchfield, J. 1974. Darwin and the dilemma of geological time. Isis, 65(3): 301-321.

Burchfield, J. 1975. Lord Kelvin and the age of the earth. New York, Science History Publications.

Burian, R. M.; Gayon, J.; Zallen, D. 1988. The singular fate of genetics in the history of French biology, 1900-1940. Journal of the History of Biology, 21(3): 357-402.

Carrisso, L. W. 1910. Hereditariedade. Dissertação manuscrita para o acto de licenciatura na Secção de Sciencias Historico-Naturais da Faculdade de Philosophia, Universidade de Coimbra [apresentada em 14 de Março de 1910].

Darwin, C. 1863. Letter 4153 - Darwin, C. R. to Gray, Asa, 11 May 1863. [online]. Darwin Correspondence Project Database. Cambridge, University of Cambridge. [Accessed 8-2-2010]. Available from: http://www.darwinproject. ac.uk/entry-4153.

Dennert, E. 1904. At the deathbed of Darwinism. [Translated by E. V. O'Hara and John H. Peschges]. Burlington, Iowa, German Literary Board.

De Vries, H. 1910. The mutation theory: experiments and observations on the origin of species in the vegetable kingdom. 2 vols. [Translated by J. B. Farmer and A. D. Darbyshire]. Chicago, The Open Court Publishing Company

Ellegard, A. 1990. Darwin and the general reader: the reception of Darwin's theory of evolution in the British Periodical Press, 1859-1972. Chicago, The University of Chicago Press.

Endersby, J. 2003. Darwin on generation, pangenesis and sexual selection. In: Hodge, J.; Radick, G. (eds.) The Cambridge companion to Darwin. Cambridge, Cambridge University Press: 69-91.

Fernandes, A. 1939. Notícia sobre a vida e a obra do Prof. Luíz Wittnich Carrisso. Boletim da Sociedade Broteriana [separata], 12 (2. ${ }^{\text {a }}$ série): XXXIII-LXXII. 
Gayon, J. 1992. Darwin et l'après Darwin: une histoire de l'hypthèse de sélection naturelle. Paris, Éditions Kimé.

Gayon, J. 2003. From Darwin to today in evolutionary biology. In: Hodge, J.; Radick, G. (eds.) The Cambridge companion to Darwin. Cambridge, Cambridge University Press: 240-264.

Gayon, J.; Burian, R. M. 2000. France in the era of mendelism (1900-1930). Comptes Rendus de l'Académie des Sciences - Series III - Sciences de la vie, 323(12): 1097-1106.

Huxley, J. 1942. Evolution: the modern synthesis. New York, Harper \& Brothers.

Lenay, C. 1996. DE VRIES Hugo 1848-1935. In: Tort, P. (ed.) Dictionnaire du darwinisme et de l'évolution. Paris, Presses Universitaires de France: 1143-1147.

Mayr, E. 1982. The growth of biological thought: diversity, evolution, and inheritance. Cambridge, Harvard University Press.

Moore, J. 1991. Deconstructing Darwinism: the politics of evolution in the 1860s. Journal of the History of Biology, 24(3): 353-408.

Pereira, A. L. 2001. Darwin em Portugal: filosofia, história, engenharia social (1865-1914). Coimbra, Livraria Almedina.

Pereira, A. L.; Pita, J. R. 1993. Ciências. In: Mattoso, J. (ed.) História de Portugal. Vol. 5. Lisboa, Círculo de Leitores: 653-667.

Ruse, M. 1983. La revolución darwinista (La ciencia al rojo vivo). Madrid, Alianza Editorial.

Ruse, M. 2002. The evolution wars: a guide to the debates. New Brunswick, Rutgers University Press.

Schmitt, S. 2002. Lucien Cuénot et la théorie de l'évolution: un itinéraire hors norme. [online]. La Revue pour l histoire du CNRS, 7: 10-16. [Consultado em 6-2-2010]. Disponível em: http://histoire-cnrs.revues.org/document535.html.

Strickberger, M. W. 1996. Evolution. 2nd edition. Sudbury, Jones and Bartlett.

Tétry, A. 1996. CUENOT Lucien Claude Jules Marie 1866-1951. In: Tort, P. (ed.) Dictionnaire du darwinisme et de l'évolution. Paris, Presses Universitaires de France: 736-743.

Tétry, A. 1964. Génétique et evolution. In: Taton, R. (ed.) Histoire générale des sciences. Tome III, Vol. II. Paris, Presses Universitaires de France: 697-715. van der Pas, P. W. 1970. VRIES, HUGO DE. In: Gillispie, C. C. (ed.) Dictionary of scientific biography. Vol. XIV. New York, Charles Scribner's Sons: 95-105.

Vieira, A. B. 2009. A evolução do Darwinismo. Lisboa, Fim de Século.

Artigo recebido a 19 de Março de 2010 e aceite a 9 de Julho de 2010. 